\title{
UNA PRIMERA APROXIMACIÓN A LA FIGURA DE CARMEN PRADA, PERIODISTA CINEMATOGRÁFICA Y EMPRESARIA EN EL MADRID DE LOS AÑOS VEINTE
}

\author{
A First Approach to the Figure of Carmen Prada, film Journalist and Businesswoman in Madrid \\ during the 1920 s \\ Víctor Rivas MORENTE ${ }^{\mathrm{a}}$ \\ Universidad Rey Juan Carlos (Madrid) \\ DOI: http://dx.doi.org/10.15366/secuencias2017.46.003
}

\section{RESUMEN}

El objetivo de este artículo es dar a conocer a Carmen Prada, una periodista cinematográfica que escribió en la prensa de Madrid entre 1918 y 1921 y que, más tarde, se dedicó a la gerencia de dos cines importantes de la capital. En este texto vamos a centrarnos, sobre todo, en la labor periodística de Carmen Prada, que firmó la mayoría de sus artículos con el pseudónimo de «Duquesa Borelli». Para abarcar toda su producción en prensa, hemos llevado a cabo una primera lectura de sus artículos y hemos seleccionado aquellos considerados más relevantes para dar a conocer su profundo y complejo conocimiento del cine de su momento. Profundo, porque Carmen Prada abordó cualquier formato en prensa para dar a conocer el fenómeno cinematográfico, desde la omnipresente gacetilla de aquellos tiempos a la entrevista o al artículo de opinión, donde demostró un amplio conocimiento del cine. Complejo, porque en toda su producción abarca todo tipo de temática relacionada con el cine: no solo la reseña más o menos breve de las películas o la consabida propaganda de las estrellas del celuloide, sino que también reflexiona sobre aspectos tan interesantes para el estudio de la recepción del cine como la estética de las películas, la labor de los directores o guionistas, el comportamiento del público en la sala o la labor de la crítica de cine, aspecto este último que convierte a Carmen Prada en una de las principales referencias de la crítica cinematográfica en Madrid y en un agente fundamental para comprender esa compleja parcela de la historiografía cinematográfica que es el estudio de la recepción del cine.

Palabras clave: crítica, historia del cine, cine mudo, cine años veinte, periodismo, mujer.

\begin{abstract}
The aim of this article is to make Carmen Prada known. A film journalist who wrote in the Madrid press between 1918 and 1921 under the alias of 'Duchess Borelli', Prada will be later the manager of two important cinema theatres in the capital. In this text I will focus on her journalistic work. In order to cover all her writings, I have carried out a first reading of her articles and selected the most relevant to make known her insightful and complex knowledge of the cinema of her time. Insightful, because Carmen Prada made use of any press format to promote cinema, from the omnipresent newsletter of those times to the interview or the opinion article, where she demonstrated an extensive knowledge of film. Complex, because in all her writings she covers all types of film-related topics: not only the relatively brief film review, or the usual star propaganda, but she also reflects on interesting aspects from the study of film reception, film aesthetics, the work of directors and writers, the behaviour of audiences in the cinema theatre, or the work of film critics. The latter turns Carmen Prada one of the main references of film criticism in Madrid and a fundamental agent to understand that complex segment of film historiography which is the study of film reception.
\end{abstract}

Keywords: criticism, history of cinema, silent movies, cinema of the 1920s, journalism, woman.

[a] Víctor Rivas Morente es licenciado en Historia por la Universidad Complutense de Madrid y doctorado en Historia del Cine Español por la Universidad Rey Juan Carlos de Madrid, con una tesis sobre la legitimación cultural y la institucionalización del cine en España a partir del estudio histórico de la crítica cinematográfica entre los años 1907 y 1920. En la actualidad continúa su investigación sobre la historia de la crítica de cine y su recepción en las primeras décadas del pasado siglo y, en concreto, centra su investigación en la aparición de las primeras mujeres que ejercieron la crítica cinematográfica. A la vez, compagina dicha labor de investigación con su trabajo como profesor titular de Historia de ESO y Bachillerato. E-mail: vicrimo@gmail.com. 


\section{Introducción}

El objetivo del presente artículo es dar a conocer la actividad profesional de Carmen Prada como periodista cinematográfica. Se trata de una primera aproximación exploratoria en la que se traza un perfil de Carmen Prada como una de las primeras mujeres que ejerció la crítica de cine en Madrid durante los años veinte del pasado siglo y que a la vez desarrolló una interesante carrera como empresaria. La importancia de su figura histórica es doble: por un lado, su actividad como periodista cinematográfica fue breve en el tiempo (apenas tres años, desde 1918 hasta 1921), aunque de una considerable intensidad, si tenemos en cuenta el número de artículos publicados y su contenido: comentarios, reseñas y críticas de películas, resúmenes de estrenos, referencias a los programas de las carteleras de los cines de Madrid, noticias relacionadas con el cine, entrevistas a profesionales del oficio y artículos de opinión sobre temas relacionados con la cinematografía nacional o extranjera; por otro lado, su trabajo como periodista culminó en 1921, aunque continuó desarrollando su actividad profesional dentro de la industria cinematográfica, primero como representante de una distribuidora y, más tarde, como gerente de los cines Royalty y Argüelles de Madrid.

El caso de Carmen Prada no es del todo aislado. En esta época nos encontramos con una mayor presencia femenina dentro del periodismo. Por supuesto, periodistas como Carmen de Burgos (Colombine) o M. ${ }^{a}$ Luz Morales (Felipe Centeno) ya han sido estudiadas por la historiografía o, al menos, sus figuras son conocidas entre las historiadoras y los historiadores de la cultura española de principios del siglo xx. Sin embargo, en el caso de estas dos periodistas, tanto Carmen de Burgos como M. ${ }^{\mathrm{a}}$ Luz Morales desarrollaron sus carreras al margen del cine. Carmen de Burgos escribió algunos artículos de temática cinematográfica, sobre todo relacionados con las actrices del momento, y publicó una novela cuya trama se desarrolla en el rodaje de una película titulada La mejor film, donde plantea las diferencias entre la producción extranjera y la producción nacional, aunque sin una verdadera intención analítica o crítica ${ }^{1}$. En cuanto a M. ${ }^{\mathrm{a}}$ Luz Morales, su producción periodística sobre el cinematógrafo fue mucho más prolífica, pues escribió una sección en La Vanguardia desde 1923 hasta 1933 aproximadamente, momento en el que desempeñó la crítica teatral en el mismo periódico, algo que ella recuerda como un ascenso profesional, lo que nos lleva a pensar que escribir sobre cine no era del todo de su agrado o, al menos, no suponía la misma consideración cultural para ella²

No obstante, tanto el caso de Carmen de Burgos como el de M. ${ }^{\mathrm{a}}$ Luz Morales, así como el que aquí vamos a exponer de Carmen Prada, se ubican en un contexto histórico de profundos cambios culturales con respecto al cine. En efecto, Carmen Prada escribió al final de la Primera Guerra Mundial, cuando la distribución cinematográfica comenzó a ser monopolizada por Hollywood frente al progresivo agotamiento de Francia e Italia, anteriores potencias industriales del cine. A la vez, a partir de este momento surgen las vanguardias históricas, cuyo espíritu rompedor en el arte conlleva la aceptación del cine
[1] M. P. Palomo, «Colombiney el cine mudo en España (La mejor filme)» (Arbor, n. ${ }^{\circ}$ CLXXXVI, junio de 2010), pp. 21-30.

[2] A. Rodrigo, Mujeres para la historia. La España silenciada del siglo XX (Madrid, Compañía Literaria, 1996). El libro de Rodrigo recoge numerosas entrevistas a mujeres protagonistas de la vanguardia en Madrid y España; por eso me he tomado la libertad de interpretar sus palabras sobre la actividad de M. ${ }^{a}$ Luz Morales como recuerdos $\mathrm{y}$, por tanto, testimonios directos de ella. 
[3] Veáse M. Dall'Asta, «El serial», en Historia mundial del cine. Vol. 1. Estados Unidos. Tomo 1 (Madrid, Akal, 2011), pp. 251-273; y C. Gledhill, «An Ephemeral History: Women and British Cinema Culture in the Silent Era», en Researching Women in Silent Cinema. New Findings and Perspectives (Bolonia, Alma Mater Studiorum, 2013), pp. 131-148.

[4] F. A. Zurián, (coord.), Construyendo una mirada propia. Mujeres directoras en el cine español. De los orígenes al año 2000 (Madrid, Síntesis, 2015).

[5] B. Soto, «Volverse invisible. Cinematógrafo, modernidad, mujer y trabajo", en Cinema $i$ modernitat: les transformacions de la recepció (Girona, Fundació Museu del CinemaCol-lecció Tomàs Mallol/Ajuntament de Girona, 2008), pp. 155-160.

[6] M. Binimelis, «Perspectivas teóricas en torno a la representación de las mujeres en el cine: una breve aproximación histórica» (Secuencias, n. ${ }^{\circ} 42$, 2015), pp. 9-34. Disponible en:. $<$ http://dx.doi.or/10.15366/secuencias2016.42.001>. como un nuevo medio de expresión artística y cultural. De esta manera, el cine consiguió una mayor legitimación cultural y social y comenzó a ocupar un mayor espacio en los medios de información, en especial en la prensa. Carmen Prada va a ser a la vez la consecuencia de este proceso de institucionalización del cine y, también, un elemento esencial para entender la causa de este esplendor, pues su actividad como periodista del cine nos va a permitir analizar mucho mejor cómo era la recepción de este en aquel momento. De hecho, Carmen Prada fue una protagonista bastante activa a favor del cine, como lo demuestran algunos de sus artículos (que más tarde comentaremos) y sus contactos con figuras consideradas pioneras en el periodismo cinematográfico y la historiografía del cine, como es el caso de Juan Antonio Cabero o Luis Gómez Mesa.

El caso de Prada es significativo de un cierto protagonismo de la mujer en la industria del cine a comienzos de la década de 1920, ya sea en la producción o en la recepción. Aun así, los estudios históricos sobre la presencia de la mujer en el cine de los primeros tiempos o en el posterior cine mudo han sido más exhaustivos en el extranjero3 ${ }^{3}$ En España, por el contrario, apenas encontramos algún trabajo de referencia sobre las mujeres directoras o, de manera indirecta, algunas alusiones a la relación entre ciertas mujeres del primer feminismo español y el cine, como el caso citado más arriba de Carmen de Burgos o M. ${ }^{\text {a }}$ Luz Morales ${ }^{4}$. Como puso en evidencia hace ya algunos años Soto ${ }^{5}$, la presencia de la mujer en el cine de los primeros tiempos es invisible para la historiografía del cine español. En este sentido, la teoría feminista del cine no ha contribuido con su epistemología a un análisis profundo del cine de los primeros tiempos, más preocupada por la época clásica de Hollywood. En efecto, fue a partir de los años ochenta cuando se fecha el giro teórico en los estudios feministas del cine, que abandonan las anteriores bases sociológicas y psicológicas para proponer un análisis institucional y cultural del contexto industrial del cine y su relación con la mujer. A partir de este momento, se comienza a realizar un análisis de la recepción femenina del cine, gracias a los trabajos pioneros de Teresa de Lauretis o Mary Ann Doane, aunque todos ellos continuaban centrados en la etapa clásica del cine de Hollywood ${ }^{6}$.

Asumiendo este contexto historiográfico y teórico, nuestro procedimiento a la hora de abordar esta primera aproximación a la figura como crítica de cine de Carmen Prada ha sido el de una exploración inicial de las fuentes hemerográficas para realizar un esbozo de su biografía y de su actividad periodística. Este trabajo exploratorio se ha realizado en tres tipos de medios: periódicos (El Día, El Fígaro, La Correspondencia de España, El Heraldo de Madrid, El Imparcial, La Libertad y La Vanguardia), revistas gráficas (Mundo Gráfico), revistas especializadas (Arte y Cinematografía, Cinema, Cine-Mundial, Cinegramas y Popular Film) y otras publicaciones como La Escuela Moderna o El Mundo Tipográfico. El uso de las fuentes se ha desarrollado en un doble sentido: por una parte, hemos utilizado fuentes para trazar una biografía profe- 
sional de Carmen Prada, en concreto, los periódicos El Heraldo de Madrid, El Imparcial, La Libertad y La Vanguardia y las revistas La Escuela Moderna, El Mundo Tipográfico, Arte y Cinematografía, Cinegramas y Popular Fỉm; por otra parte, hemos analizado de forma más exhaustiva, aunque siempre con el carácter aproximativo de este trabajo, los artículos de Carmen Prada en El Día, El Fígaro, La Correspondencia de España, Cinema, Cine-Mundial y Mundo Gráfico. Todo ello nos ofrece una panorámica lo suficientemente profunda como para destacar la importancia de Prada en el estudio de la recepción del cine de los años veinte en Madrid y en España.

\section{Una primera biografía de Carmen Prada}

El nombre completo de Carmen Prada era Carmen Prada Mantrana7. De la fecha de nacimiento de Carmen Prada nada sabemos aún debido al carácter inicial de esta investigación. Pero, ateniéndonos a la fecha de inicio de su actividad como periodista, en torno a 1918, podríamos intuir que comenzó hacia los veinte o treinta años de edad. Podemos inferir que, quizás, su nacimiento fuera a finales del siglo xix, en torno a la década de 1890.

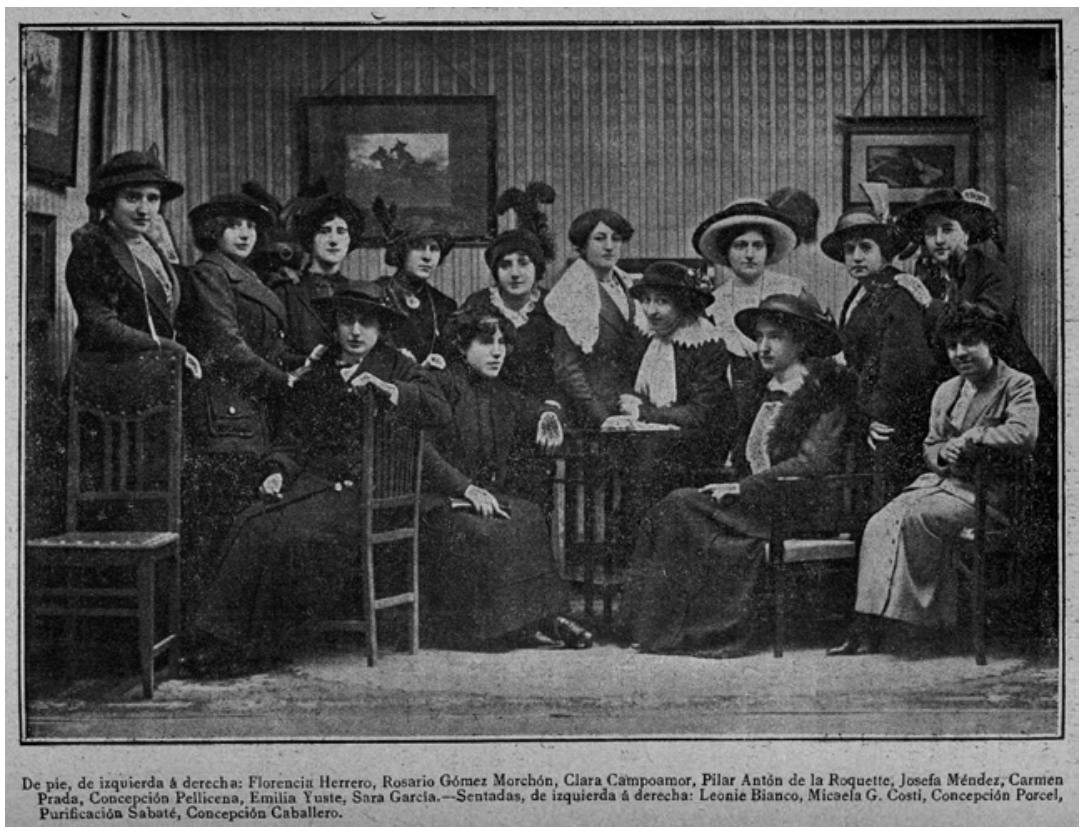

Carmen Prada en una imagen de su promoción de profesoras de taquigrafía y mecanografía.

Conocemos algunos datos sobre su formación intelectual. Parece ser que poseía una titulación académica y que ejerció como profesora de taquigrafía y mecanografía desde 1914 en la escuela de adultas de Barcelona. En la revista El Mundo Taquigráfico ${ }^{8}$, aparece un extenso artículo sobre las recién nombradas
[7] He podido relacionar a Carmen Prada con el apellido Mantrana gracias a la ayuda inestimable de la profesora Begoña Soto, que me proporcionó una imagen del contrato que Carmen Prada realizó en 1927 con la distribuidora Casa $\mathrm{Hu}-$ guet, en el que aparece su firma y el nombre «Carmen Prada Mantrana». La imagen de dicho contrato está incluida en este artículo (p. 81).

[8] Anónimo, «Las profesoras de taquigrafía y mecanografía» (El Mundo Taquigráfico, n. ${ }^{\circ}$ 167, 15-02-1914), pp. 33-39. 
[9] Veáse Anónimo, «Profesoras de taquigrafía» (La Vanguardia, 18-02-1914), p. 10.

[10] El primer dato que me confirmó la autoría de Carmen Prada bajo el seudónimo de Duquesa de Borelli fue una breve alusión en una entrevista concedida por Juan Antonio Cabero en la revista Cinegramas : «[...] Pero se daba el caso absurdo de que ninguno de los redactores cinematográficos concurría a las pruebas de películas. Puede decirse que solo asistíamos Carmen Prada, que se firmaba Duquesa de Borelli, y yo [...]» (M. Torres, «Apuntes para la historia del cinema español. Juan Antonio Cabero, decano de los periodistas cinematográficos de Madrid» [Cinegramas, $\left.\left.n^{0} 67,22-12-1935\right]\right)$. El segundo dato que conecta a Carmen Prada con el seudónimo de Duquesa de Borelli es el pie de foto de un retrato suyo aparecido en el número especial de Arte $y \mathrm{Ci}$ nematografía dedicado al cine en Madrid, donde se lee: «Srta. Carmen Prada que, con el seudónimo de Duquesa de Borelli, ha realizado en cinematografía interesante labor periodística» (T. M., «Valores positivos» [Arte y Cinematografía, n. ${ }^{\circ}$ 300, 1926]). profesoras de Taquigrafía y Mecanografía de esta promoción, donde se cita a Carmen Prada junto al resto de profesoras, entre las cuales también se encontraba Clara Campoamor, destacada política y activista feminista de la época. En este artículo también aparece una fotografía de promoción, incluida en este artículo, y una breve biografía intelectual de cada profesora. De Carmen Prada se destaca que en, 1900, estudió taquigrafía con el profesor D. Pedro Cerdán y que, entre 1902 y 1914, estuvo trabajando como taquígrafo-mecanografista en la fábrica de material ferroviario Casa Orenstein y Koppel-Arthur9.

Su actividad periodística como cronista del cine comenzó en 1918 bajo el seudónimo de «Duquesa de Borelli» ${ }^{10}$. Hacia finales de 1921 parece ser que terminó su actividad como periodista, o, al menos, no hemos encontrado ninguna publicación suya a partir de esa fecha. Sospechamos que volvió a trabajar como profesora en la escuela de adultas de Barcelona debido a una información en La Vanguardia ${ }^{11}$ en la cual se informa sobre la obtención de un ascenso como profesora de francés. Sin embargo, no abandonó su trabajo dentro de la industria del cine. Entre 1922 y 1925 asumió la gerencia del cine Royalty de Madrid y, a partir de 1925, del cine Argüelles, que fue inaugurado por esa misma época ${ }^{12}$. Hacia 1927, también se convirtió en representante de la distribuidora Casa Huguet en Madrid, con lo que completaba su actividad profesional dentro de la distribución y exhibición de películas ${ }^{13}$. Las referencias a Carmen Prada durante la década de los treinta que he podido consultar hasta el momento son más confusas y, en cualquier caso, no aportan información relevante con respecto a su actividad en la industria cinematográfica ${ }^{14}$.

[11] Anónimo, «De enseñanza nacional» (La Vanguardia, 21-08-1924), p. 16.

[12] El único que aporta información sobre la gerencia del cine Royalty es Gómez Mesa: «Hasta que en inolvidable día se solicita su concurso para regir los destinos del aristocrático coliseo madrileño Royalty. Carmen acepta la proposición y, durante quinquenio y pico, maneja las riendas del elegante salón de espectáculos [...]» (L. Gómez Mesa, «Gracias, infinitas gracias, señorita Carmen Prada» [Popular Film, n. ${ }^{\circ}$ 34, 24-03-1927], pp. 1-2). Sin embargo, he sido incapaz de contrastar este dato de Gómez Mesa con otras fuentes.

[13] Para la actividad de Carmen Prada como gerente del cine Argüelles, veáse: Anónimo, «Noticiario» (El Imparcial, 02-05-1925); confirmado también en: J. K., «Cosas de casa y por los de casa» (La Libertad, 17-11-1926), p. 6; y Anónimo, «El homenaje a Freixes» (El Heraldo de Madrid, 24-11-1926). Para su trabajo como corresponsal de la Casa Huguet existe la prueba del contrato firmado en 1927, ya referenciado en este trabajo, así como en Anónimo, «Noticiario» (El Imparcial, 13-08-1927): «Ha sido nombrada gerente en Madrid de la Casa Huguet la señorita Carmen Prada, que en tantos aspectos del séptimo arte ha logrado destacar su personalidad».

[14] Entre 1932 y 1933 se nombra a una tal Carmen Prada, sin especificar segundo apellido, como presidenta de la Asociación Femenina Ciudadana en Zamora, la cual es catalogada como «bloque de derechas» y, en concreto, ella es referida como «destacado elemento derechista». De hecho, aparece en un ciclo de noticias relacionado con un intento de incendio de su coche por parte de un grupo de izquierda radical en Mencheta: «Doña Teresa Luzzati dijo que la mujer debe decidirse a "manejar" el voto femenino, que es un arma de dos filos» (La Nación, 20-o6-1932), p. 2; Anónimo, «Varios actos de propaganda política y social» (El Sol, 31-01-1933); y Anónimo, «Actos de propaganda política» (La Libertad, 3101-1933). Más allá de la veracidad de esta información, varios aspectos no concuerdan con nuestra Carmen Prada Mantrana, uno de los cuales es, evidentemente, que no tenemos el dato del segundo apellido; además, y esto también es relevante, Carmen Prada siempre se movió entre Barcelona y Madrid, y su conexión con una provincia como Zamora resulta algo confusa. No obstante, sí que es cierto que Carmen Prada parece haber tenido contacto con asociaciones feministas, como lo demuestra su docencia en la escuela de mujeres adultas de Barcelona junto a Clara Campoamor o sus artículos en defensa de las «casas-cuna» en El Día a principios de 1918. Las últimas noticias sobre Carmen Prada son aún más cuestionables. Se nombra a una Carmen Prada y Mandrana (¿error tipográfico?) en octubre de 1936 en La Vanguardia, cuando ya había estallado la Guerra Civil. La noticia informa sobre la vuelta a la docencia de esta mujer, lo que sí que tendría más sentido en el caso de nuestra Carmen Prada. Aun así, más confusa es la última noticia, encontrada en el periódico La Solidaridad Obrera, en diciembre de 1937, donde aparece el nombre de Carmen Prada Montrana (¿de nuevo error tipográfico?) en una breve nota, muy confusa, en la cual se convocan a varias personas en Barcelona para la Bolsa de Trabajo de Euzkadi. La noticia no aclara nada más. Por supuesto, seguiré investigando la validez de todos estos datos. 


\section{La actividad como periodista de Carmen Prada}

La labor de Carmen Prada como periodista cinematográfica se prolongó durante tres años, desde noviembre de 1918 a noviembre de 1921, a lo largo de su colaboración en seis medios: tres periódicos de tirada nacional (El Día, El Fígaro y La Correspondencia de España), una revista gráfica (Mundo Gráfico) y dos revistas especializadas en cine (Cine-Mundial y Cinema). En todos ellos utilizó el seudónimo de «Duquesa Borelli», excepto en Cine-Mundial. En total hemos recopilado ochenta y nueve artículos, lo que es una cantidad considerable si tenemos en cuenta la todavía intermitente presencia de los periodistas sobre cine en la prensa generalista de esa época y, sobre todo, la escasa o nula presencia de la mujer como periodista y, aún más, como periodista cinematográfica.

Los primeros artículos que hemos consultado de Prada corresponden a su colaboración en el diario El Día, un periódico de información general, sucesor de los anteriores El Día (1880) y El día de Madrid (1908-1916). Contenía un gran cuidado gráfico, y su temática e ideología eran conservadoras y monárquicas (durante la Primera Guerra Mundial defendió posiciones germanófilas). Entre los colaboradores más relevantes destacaron Miguel de Unamuno, Pardo Bazán, Antonio Hoyos Vinent, Eduardo Zamacois, Margarita Nelken, José Ortega y Gasset o Ramón Gómez de la Serna, entre otros. Tenía una tirada aproximada de unos 14.00o ejemplares ${ }^{15}$.

Prada firmó como la Duquesa de Borelli un total de veintiún artículos para El Día, en una sección del periódico dedicada al cine que tuvo tres nombres distintos: «El mundo cinematográfico», «La vida del cine» (los lunes) y «Cosas del cine» (viernes o sábados). A partir de enero de 1919 la sección pasó a llamarse «Cosas del cine» y, para febrero de 1919, ya adquirió el nombre de «Por esos cines». Prada colaboraba con una columna propia que se llamaba «Hojas sueltas de mi álbum», la cual nunca cambió de nombre durante los cuatro meses que permaneció en el periódico, entre noviembre de 1918 y febrero de $1919^{16}$. Los temas de estos artículos se pueden organizar en: reseñas o comentarios más o menos amplios sobre los estrenos; comentarios sobre las películas exhibidas en lo que se denominaba "pases de prueba», es decir, pases para la prensa; noticias sobre el mundo del cine; y opiniones sobre temas diversos de la cinematografía, entre los que destacan artículos dedicados al periodismo cinematográfico, la música durante la proyección, la censura y la moralidad en el cine, la defensa del futuro del cine y el mundo de las actrices. En algunos casos, los artículos no se conservan en buen estado y su lectura es dificultosa, pero en su totalidad nos muestran una evolución de la reflexión de Prada sobre el cine, que abandona poco a poco la excesiva presencia del resumen del argumento de las películas por una mayor profundidad en el análisis de las imágenes.

De la evolución del pensamiento de Carmen de Prada sobre el cine y, en consecuencia, de una mayor profundidad en su crítica cinematográfica da buena cuenta su colaboración, a partir de abril de 1919, en el periódico El Fígaro, un periódico matutino con apariencia de magazine, gracias a su buena presen-
[15] Hemeroteca Digital de la Biblioteca Nacional, <http://hemerotecadigital.bne.es/details.vm?q= id: $0003467109 \&$ lang $=$ es $>$

[16] Hay que advertir que, si bien Prada comenzó su colaboración firmando su primer artículo como la Duquesa de Borelli el 18 de noviembre de 1918 , hubo cuatro ocasiones en las que no firmó su columna, en concreto las de los días 23, 25 y 29 de noviembre y la del 25 de diciembre de 1918. Aun así, no dudamos de la autoría de dichos artículos; en primer lugar, porque mantienen el título de su columna, «Hojas sueltas de mi álbum»; y, en segundo lugar, porque utiliza el mismo tono y estructura en su introducción, siempre refiriéndose a las lectoras. 
[17] M. C. Seoane y M. ${ }^{a}$ D. Sáiz, Historia del periodismo en España. 3. El siglo XX: 1898-1936 (Madrid, Alianza Editorial, 1998); y Hemeroteca Digital de la Biblioteca Nacional. Disponible en: <http://hemerotecadigital.bne.es/details.vm? q=id:0031396058\&lang=es > tación y cuidado gráfico. Salió a la calle tres meses antes de finalizar la Primera Guerra Mundial y mantuvo una temática liberal, demócrata y social que le llevó a defender la actividad sindical obrera y dar cobertura a la acción política del PSOE. Algo significativo es que fue uno de los periódicos que fomentó la colaboración de mujeres en sus páginas, como lo demuestra el hecho de que mantuviera una sección llamada «Mujeres en guerra» o que en sus páginas escribiera María de Lluria, una de las primeras feministas españolas, apodada «la marquesa roja». Entre otros colaboradores ilustres que escribieron en sus páginas destacan Indalecio Prieto, Margarita Nelken, Luis Araquistáin, Rafael Altamira, Salvador de Madariaga, Luis Bello, Manuel Azaña o Josep Pla. Su tirada aproximada era de entre siete mil y ocho mil ejemplares ${ }^{17}$.

En El Fígaro, Carmen Prada gozó de una mayor libertad para escribir sobre cine, ya que fue la encargada de llevar toda una sección, «Páginas cinematográficas», aunque mantuvo el seudónimo de «Duquesa de Borelli». En total fueron veintiún artículos los que firmó en El Fígaro, de forma regular y con una estructura en la sección bastante sólida, pues mantuvo dos secciones de forma permanente: una, llamada «... Al vuelo», donde recogía noticias sobre el mundo del cine; y otra, llamada «De "cine en cine"», en la que opinaba sobre los estrenos de la cartelera. Estas dos secciones eran prácticamente similares a las que había escrito en El Día. Sin embargo, la línea editorial del periódico, de ideología más progresista y democrática que El Día, pudo influir en la nueva manera en la que Prada abordó sus textos sobre el cinematógrafo. En efecto, siguió dedicando columnas a las críticas de películas, aunque ahora sus resúmenes eran más densos y, en algunos casos, se abordaba el comentario de películas concretas. No obstante, junto a las secciones habituales sobre las noticias relacionadas con actrices o actores («Chismografía»), introdujo textos más reflexivos sobre toda clase de temas relacionados con la industria del cine como, por ejemplo: las implicaciones del final de la Primera Guerra Mundial para el futuro de la distribución en Europa y España, los oficios dentro del cine, la situación del sector de la distribución y de la exhibición, la función moral y educativa del cine, la situación del periodismo cinematográfico o la actualidad de la cinematografía española.

Su colaboración para El Fígaro es la que contiene una mayor importancia historiográfica por su regularidad, autoría y amplitud temática. El hecho de que fuera la única redactora de la sección da cuenta de su profundo conocimiento sobre la industria del cine y su recepción. Además, la variedad de temas que trata en su sección demuestra una amplia erudición cinematográfica, un dominio de la producción nacional y extranjera y un mayor rigor y especialización sobre el cine, con el uso de conceptos y nombres mucho más específicos. No obstante, también somos conscientes de que esta amplitud de temas conlleva una escasa especialización crítica y aún observamos el predominio del resumen de argumentos de las películas, así como una mayor preocupación por las noticias sobre el star system.

En enero de 1920, al finalizar su colaboración con El Fígaro, continuó escribiendo para la revista Cine-Mundial como corresponsal en Madrid. Cine- 
Mundial fue la versión española de Moving Picture World, una de las revistas estadounidenses más famosas. Al parecer, se publicó desde 1916 hasta 1948, y su temática tuvo una fuerte carga promocional, pues en sus páginas se publicitaba el cine de Hollywood para su distribución y exhibición en Latinoamérica y España. A su vez, también era una publicación comercial para aficionados al cine, por lo que incluía el estreno de películas, en su mayoría estadounidenses, en las carteleras de las principales ciudades de Latinoamérica y España. De ahí el trabajo de Carmen Prada como corresponsal en Madrid ${ }^{18}$.

Prada escribió un total de cinco artículos para Cine-Mundial a lo largo de 1920, los meses de enero, marzo, abril, julio y octubre. Todos ellos los escribió en la sección de la revista titulada «Crónica de Madrid», de la cual era la única redactora. Lo más significativo es que, en esta ocasión, utilizó su nombre y no los firmó con seudónimo. La única razón que se nos ocurre es que la revista así lo exigiera para dar una mayor visibilidad internacional a sus colaboradores, lo cual también supone deducir que escribir en Cine-Mundial era más legítimo y, por lo tanto, era más conveniente darse a conocer sin ocultarse bajo un seudónimo. En todo caso, los artículos de Carmen Prada para Cine-Mundial se reducen a breves comentarios sobre los estrenos en la cartelera de Madrid, a alguna noticia interesante relacionada con la producción nacional o el mundo del cine patrio y a los comentarios sobre los «pases de prueba». No obstante, conviene destacar que los artículos de opinión versaron sobre las relaciones entre el teatro y el cine (una temática que nos recuerda a los primeros tiempos de la prensa cinematográfica) y, por supuesto, sobre las relaciones entre la industria estadounidense y la española, obedeciendo la línea editorial marcada por la revista.

Entre julio y noviembre de 1920, en alternancia con su trabajo como corresponsal de Cine-Mundial, Carmen Prada colaboró como periodista cinematográfica con el popular periódico nacional de tendencia liberal moderada $L a$ Correspondencia de España, lo que nos hace deducir que fue un ascenso profesional, ya que dicho periódico era uno de los decanos de la prensa nacional y uno de los diarios más vendidos en todo el país. De esta manera, suponemos que los escritos sobre cine de Carmen Prada tuvieron una mayor proyección entre el público lector.

En total fueron nueve artículos bajo la columna «Los últimos estrenos» (excepto la primera colaboración que tuvo como título «La muñeca») en la sección del periódico dedicada al cine llamada «Cinematografía». En general, son resúmenes de los argumentos de algunas de las películas estrenadas en la cartelera, aunque en ciertos comentarios encontramos referencias a las cualidades plásticas de las películas y, sobre todo, a la valoración general que el público hacía de la película, lo que supone una valiosa documentación para el análisis de la recepción del cine en Madrid en los años veinte.

En este mismo año de 1920, también escribió un texto para la efímera revista madrileña Cinema, de la que solo se tiene constancia de la existencia de un número. Carmen Prada escribió un artículo titulado «El niño en el cine», en el que realiza una defensa del valor moral del cine y del que nos ocupare-
[18] Para un conocimiento más profundo sobre Cine-Mundial, véase L. I. Serna, «Descripción», en Media History Digital Library (<http://lantern. mediahist.org/catalog/cinemundial19unse_0154>). 

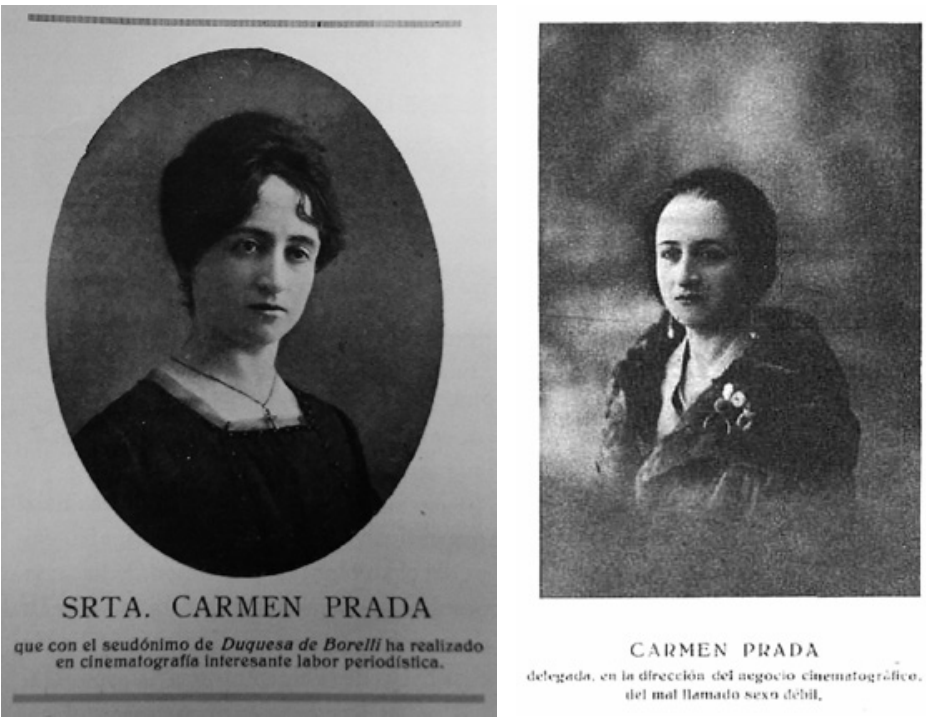

CARMEN PLADA

detcracta. en in dirección det aegosio cinematogrifico. tel mal llamado sexo debil.

Fotografías de Carmen Prada en 1926 y 1927.

mos con mayor atención más adelante.

La última colaboración de Carmen Prada como periodista cinematográfica que presentamos en este artículo es la que realizó para la revista gráfica Mundo Gráfico, una de las más populares de Madrid y España. En total fueron catorce artículos entre mayo y noviembre de 1921, en la sección «Peliculerías» y firmados como la «Duquesa de Borelli». Quizás sean sus artículos más reflexivos, ya que todos ellos son opiniones sobre aspectos del cine: contra la división de sexos en las salas, la defensa de la producción nacional, el valor educativo del cinematógrafo, el valor de las actualidades y del cinematógrafo, un reportaje sobre el estreno de El gabinete del Dr. Caligari (Das Cabinet des Dr. Caligari, Robert Wiene, 1920) en Nueva York y una reflexión histórica sobre el origen del cine. En todos ellos, Prada demuestra ya una mayor madurez en sus comentarios y análisis, fruto de una progresiva y sólida actividad periodística. Son, junto con sus textos para El Fígaro, sus artículos más representativos y, por lo tanto, de mayor interés para un estudio sobre la recepción del cine y el valor historiográfico de la crítica de cine.

\section{Carmen Prada y la crítica cinematográfica}

El primer artículo al que nos vamos a referir a continuación fue publicado en El Día el 30 de diciembre de 1918, en la página cuatro, bajo el título de «Hojas sueltas de mi álbum», columna habitual de Prada en dicho rotativo que se ubicaba en la sección «La vida del cine». Del texto podemos destacar dos partes: una crítica de la película Susana (The Rise of Susan, Stanner E. V. Taylor,

[19] Susana se estrenó en el Cine Cataluña de Barcelona, donde precisamente la vio Carmen Prada, como alude en su texto: «Recordamos siempre con singular deleite una obra cinematográfica [...], que vimos en el "Cine Cataluña", de la ciudad condal, hará un par de años».
1916) y una reflexión sobre la crítica cinematográfica ${ }^{19}$.

En cuanto a la crítica de la película Susana, conviene destacar la introducción de su sección, dirigida a las mujeres: «¿Quieren nuestras bellas amiguitas que echemos hoy un parrafillo acerca de las películas que más nos agradan?»; luego, continúa con la defensa de lo que ella llama «películas sentimentales», que diferencia de las películas «cómicas», «novelescas», de «aventuras», «instructivas» $\mathrm{y}$ «dramáticas». Para justificar su gusto por la películas «sentimen- 
tales», recurre al recuerdo de la visión de la película Susana, a la cual describe como un «poema» de amor y de ternura, capaz de trasmitir la «firmeza en el cariño» y la fidelidad. Otro valor que destaca de esta película es su originalidad al prescindir de un final feliz, algo recurrente en este tipo de relatos:

Contra lo que siempre acontece en novelas, comedias, cuentos, dramas y toda la gama de la literatura -es decir, que al final todo se arregla a entera satisfacción de los protagonistas- en esta exquisita producción del «cinema» la simpática heroína perdía la vida [...].

Pero la parte más interesante de este artículo de Prada es la dedicada a la situación de la crítica cinematográfica. Comienza realizando una reivindicación de la importancia de la crítica cinematográfica justificada por el éxito cada vez más evidente del cine entre el público. Continúa con una comparación entre la crítica de cine y la crítica de teatro. Primero, destaca aquellos elementos que, en su opinión, la crítica de cine ha recogido de la crítica teatral para realizar sus valoraciones: la actuación, la puesta en escena y la música, si existe. Después, establece las diferencias entre la crítica de teatro y la crítica de cine, que tienen que ver con la mayor complejidad de la imagen cinematográfica:

Para hacer la crítica de una obra teatral basta con verla una vez, generalmente. Para hacer la de una película es menester verla varias veces, porque la rapidez con que en la pantalla se suceden las escenas, unida a la atención con que hay que seguir las actitudes de los actores para darse exacta cuenta del argumento -no para todas las películas los imprimen y reparten-, hace que en una sola representación puedan escaparse detalles dignos de censura, de la mise en scène, del vestuario, etc.

Aquí, Prada plantea la nueva mirada que debe adoptarse ante el cine, una mirada que requiere una recepción más reflexiva que la del teatro, donde la concentración debe ser más aguda por parte del espectador; a su vez, la película permite y obliga, parece querer decir Prada, a verla más de una vez para captar todos sus matices.

Estas reflexiones de Carmen Prada sobre la situación de la crítica cinematográfica en esos años no deben sorprendernos, ya que mantuvo una relación profesional, al parecer bastante estrecha, con algunos de los periodistas cinematográficos más conocidos de su época o, al menos, algunos de los que la historiografía se ha ocupado con mayor profundidad: Cabero, Gómez Mesa y Fréixes (director de Arte y Cinematografía). A su vez, su trabajo como corresponsal para Cine-Mundial vendría a señalar la solidez de la posición de Prada en el mundo del periodismo madrileño de los primeros años veinte del siglo pasado. En efecto, en esta época, el periodismo cinematográfico cobra mayor relevancia asociado a la irrupción de las vanguardias artísticas. Si, con anterioridad, la historiografía cuestiona la existencia de una crítica cinematográfica sobre todo por su carácter corporativo, su tono desenfadado y su ambigüedad interpretativa ${ }^{20}-$, en los años veinte parece que se acepta la existencia de una cierta crítica cinematográfica más preocupada por el discurso artístico del cine, [2o] J. M. Minguet Batllori, Paisaje(s) del cine mudo en España (Valencia, Ediciones de la Filmoteca, 2008). 
[21] J. M. Minguet Batllori, «Las vanguardias históricas y el cine español», en Un siglo de cine español (Madrid, Academia de las Artes y las Ciencias Cinematográficas, 2000), pp. 65-79.

[22] Véase J. M. Minguet Batllori, «Las vanguardias históricas y el cine español», pp. 65-79; A. Hernández Eguíluz, Testimonios de huecograbado. El cine en la $2^{a}$ República y su prensa especializada (1930-1939) (Valencia, Ediciones de la Filmoteca, 2009); M. García Carrión, Por un cine patrio. Cultura cinematográfica y nacionalismo español (1926-1936) (Valencia, Publicacions de la Universitat de València, 2013).

[23] Duquesa de Borelli, «Páginas cinematográficas» (El Fígaro, 31-o8-1919), p. 2. iYo acuso! se estrenó en Madrid a principios de 1921. Véase A. Insua, «El iYo acuso!, de Abel Gauce [sic]» (La Correspondencia de España, 08-01-1921). en consonancia con el elitismo cultural exhibido por los intelectuales de vanguardia del momento. Así, los futuristas, cubistas, surrealistas y altruistas legitimaron culturalmente el cine al organizar actividades, manifestaciones, textos y exposiciones sobre la cinematografía. De esta manera, el cine es aceptado como un fenómeno cultural, un nuevo mecanismo de expresión y un elemento fundamental de la modernidad, rasgos que encontramos en los artículos de Carmen Prada ${ }^{21}$.

Carmen Prada pudo escribir sobre cine gracias a un contexto institucional favorable, con la consolidación y aparición de más publicaciones dedicadas exclusivamente a la cinematografía, como el caso de Arte y Cinematografía, El Cine, Popular Film, Film Selectos, Nuestro Cinema, Cinegramas, Proyector, Cinema Variedades e Información Cinematográfica. Una muestra de este interés de la alta cultura intelectual por el cine fue la aparición de numerosas revistas mucho más especializadas que, si bien, en la mayoría de la ocasiones, tuvieron una vida efímera, dieron constancia, por su proliferación, de la mayor importancia que, dentro de la intelectualidad, había conseguido el cine: Siluetas, Cinema, Super-Cine, Cine Arte, Cine-Art, Filmópolis, Cine Español, Sparta, Andalucía Film, Cine-Star y Nuevo Cinema. A su vez, la aparición del concepto del cine club como espacio de debate crítico y teórico sobre el cine posibilitó la creación de una cultura cinematográfica más especializada y la posibilidad de exhibir producciones que se consideraban vanguardistas por su mayor relación con la intelectualidad del momento. A ello ayudaron el Cine Club Español de Madrid, apoyado por la revista La Gaceta Literaria de Ernesto Giménez Caballero; o el Cine Club Mirador de Barcelona, apoyado a su vez en la revista Mirador. Por lo tanto, la crítica ocupa un mayor espacio en la prensa de los años veinte, aparecen más periodistas que se autodenominan críticos, como el caso de Carmen Prada, y se publican más libros sobre cine, todo ello en un ambiente cultural que culmina con la celebración del primer Congreso Español de Cinematografía en 1926, al que asistieron críticos tan cercanos a Carmen Prada como Gómez Mesa y Fernández Cuenca, entre otros ${ }^{22}$.

De la puesta en práctica de una actitud más reflexiva hacia las películas por parte de Carmen Prada es un ejemplo paradigmático su crítica de la película Yo acuso (J'acusse!, 1919) de Abel Gance, visionada en un "pase de prueba» para El Fígaro (31-08-1919) ${ }^{23}$. En la primera parte de su crítica, Prada demuestra un conocimiento previo sobre la recepción en prensa de la película y la trayectoria cinematográfica de Abel Gance. Alude a las controversias en la prensa francesa en torno a su estreno, lo que sugiere un interés especial de Prada por esta película en concreto. Además, reconoce que la ha visto en «prueba privada» (pase de prensa) y transmite cierta predilección por el cine de Abel Gance, un director del que cita otros títulos de su filmografía: «La personalidad artística de Abel Gance, briosamente acusada en otras cintas - La zona de la muerte y La décima sinfonía, entre ellas- se consolida reciamente en esta». Esta alusión a la filmografía concreta de un director y su valoración como «artista» es de gran importancia, pues supone una de las primeras muestras de legitima- 
ción cultural del cine por parte del periodismo, a la vez que ubica a un director dentro del concepto elitista de artista. Se trata de una valoración artística del cine a través de la valoración crítica de una película considerada única y original.

A continuación, Prada divide su crítica en tres partes. En la primera, realiza una declaración de su tesis sobre la película: «iYo acuso! es una bellísima manifestación de arte en que la fantasía de Gance ha corrido libre, suelta, componiendo unos maravillosos cuadros llenos de Poesía y Amor, a base de un argumento vigoroso y de profunda tesis».

De esta manera, Prada divide su valoración de la película en dos elementos: la calidad artística de la imagen, por un lado, gracias a la libertad y a la fantasía de Abel Gance; y la importancia de su argumento, por otro, gracias a la profundidad del tema que plantea.

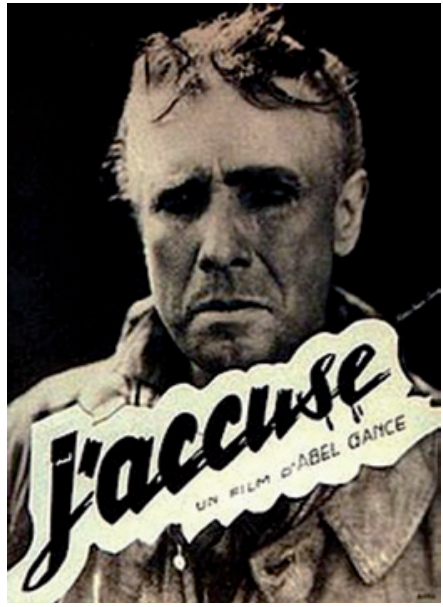

Cartel de Yo, acuso (J'accuse!, Abel Gance, 1919).

Qué duda cabe que Prada dedica una mayor extensión en su crítica al análisis y valoración del argumento de la película. Para ella, la trama supone un gran hallazgo, porque plantea una crítica humanitaria contra la guerra. Pero no se limita a una simple declaración de sus gustos, sino que los justifica a través de la transcripción de textos del propio guion de la película: «En la última parte de su obra pone Gance en labios de Juan Díaz esta escalofriante imprecación: “... y los muertos vienen ahí, detrás de mí, a ver qué habéis hecho de su gloriosa memoria y si sois dignos del sacrificio que ellos han realizado" ${ }^{24}$.

No obstante, Prada no se limita a una simple valoración del argumento, sino que propone una reflexión sobre la Primera Guerra Mundial y sus consecuencias, utilizando para ello la película de Abel Gance, lo que vendría a probar la idea que ella poseía sobre la crítica cinematográfica y, por consiguiente, sobre el cine, basada, como ya hemos visto, en una mayor reflexión sobre las películas. En este sentido, conviene destacar que, en esta crítica, Prada ofrece su opinión sobre la controversia que suscitó el film en la prensa francesa:

Por algunos se ha reputado esta obra en Francia de falta de patriotismo. No estamos conformes, tal vez porque nuestra calidad femenina nos hace mirar con más egoísta amor las vidas de nuestros maridos, de nuestros padres, de nuestros hijos, de nuestros hermanos [...]. En nuestro sentir, lo que palpita en ella, de principio al fin, es una sublime y vehemente ansia de ver al hombre purificado hasta el punto de que no reconozca fronteras ni nacionalidades.

La alusión a su "calidad femenina» introduce en la crítica un posicionamiento de género que no debe pasar desapercibido y que abordaremos más adelante. Ahora, nos contentaremos con mostrar la profundidad del análisis crítico de Prada, donde la valoración y la reflexión conviven en armonía con su idea de la crítica cinematográfica, lo cual otorga una mayor madurez a su discurso. Más adelante, alude a otros aspectos morales de la película que, según

[24] Cabe la posibilidad de que, en efecto, Prada cite de memoria, aunque también puede ser una cita literal del programa de mano que la propia distribuidora habría entregado entre los periodistas para el visionado del pase de prensa. 
ella, deben destacarse, como son las relaciones amorosas en el matrimonio de los personajes de Laura y Juan Díaz, que Prada califica como «anormales» aunque no las condena, sino que las defiende como algo positivo- así como el respeto hacia los soldados y los fallecidos en la guerra que muestra Abel Gance, algo que refuerza la calidad humana de su argumento.

Por último, Prada realiza una apreciación de los elementos formales y de la actuación en la película, aunque los despacha en un escueto párrafo: «La interpretación por parte de los artistas y la ejecución, en sus aspectos técnico y artístico, es estupenda. La fotografía es maravillosa, de una delicadeza y perfección incomparables». También valora, de manera general, la veracidad, crudeza y riesgo formal de las escenas de la película y menciona dos de ellas, aunque no las describe ni las especifica. No obstante, debido a esta originalidad, cree que, quizás, la película no será exhibida: «Por ello, a la hora de trazar estas líneas, ignoramos y dudamos si habrá alguna empresa que se atreva a proyectarla». $\mathrm{Al}$ final, concluye con una valoración de la película: «En resumen: un triunfo rotundo para el teatro mudo francés».
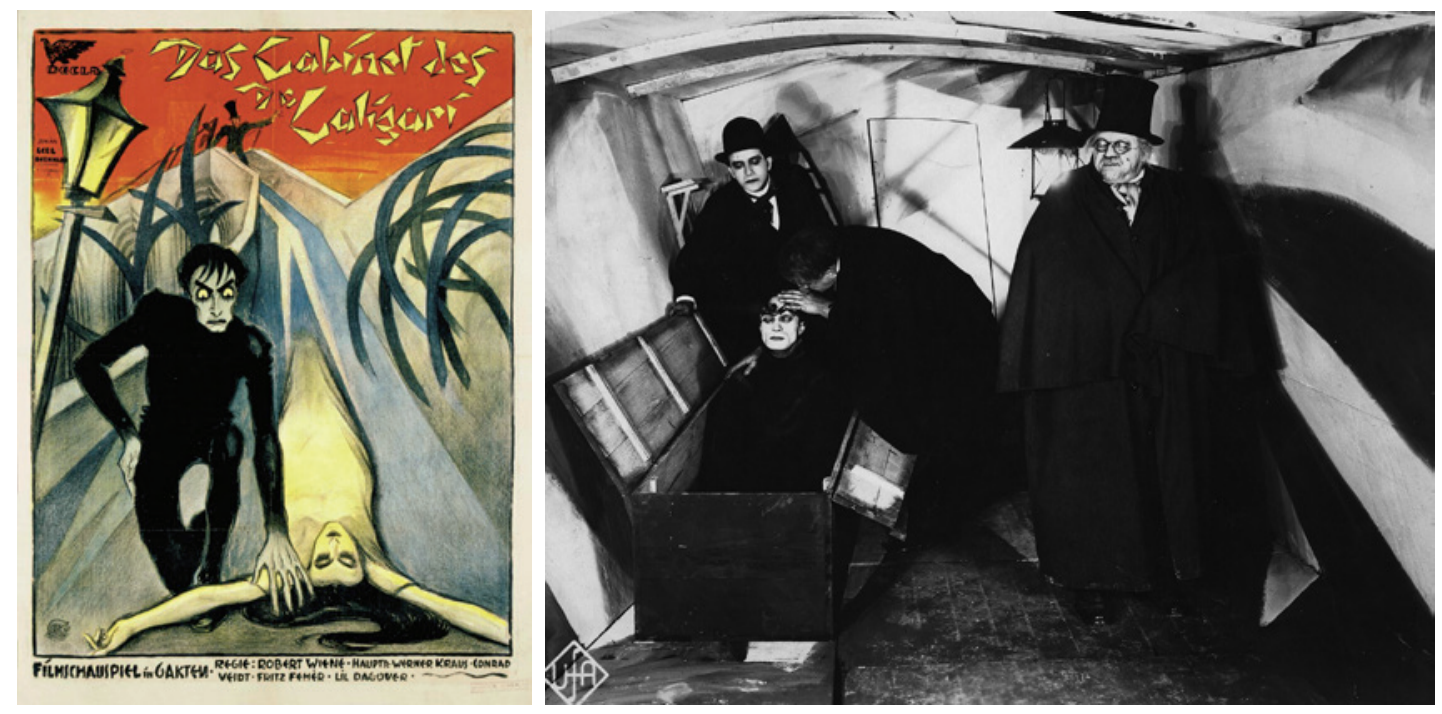

Cartel y fotograma de El gabinete del Dr. Caligari (Das Cabinet des Dr. Caligari, Robert Wiene, 1920).

[25] Duquesa de Borelli, «Peliculerías» (Mundo Gráfico, o106-1921).
Posteriormente, en Mundo Gráfico (01-06-1921) ${ }^{25}$, realizó un comentario sobre el estreno de El gabinete del doctor Caligari en Nueva York. En este caso no podríamos hablar de una crítica de la película, como en el caso anterior de Yo acuso de Abel Gance, sino de una noticia en la que Prada introduce algunos comentarios sobre la importancia del film. Sin embargo, vendría a reafirmar su conocimiento sobre la producción cinematográfica y el grado de profesionalización de su actividad como periodista cinematográfica. Al comienzo del artículo nos ofrece su interés por la actualidad cinematográfica 
con la información del estreno de la película: «La première de la extraordinaria producción cinematográfica El gabinete del doctor Caligari, celebrada en el Teatro Capitolio de New-York, ha revestido todos los caracteres de un acontecimiento». Además, muestra su dominio de la prensa cinematográfica con alusiones a las opiniones de los periódicos y revistas extranjeros: «Los periódicos y revistas, sin distinción de matices, dedican calurosos elogios a esta película $[\ldots]{ }^{26}$.

$\mathrm{Al}$ final de su noticia sobre este estreno, Prada realiza algunas impresiones sobre el film, basándose, quizás, en una selección de los que ha leído en la prensa, lo que nos parece más probable teniendo en cuenta su experiencia durante tres años como periodista cinematográfica: «[destaca la] fidelidad y el realismo con que se ha trasladado a la pantalla este episodio [...], y los modernísimos métodos de impresionismo que se han puesto en práctica para lograr efectos fotográficos desconocidos hasta ahora».

Es cierto que, comparada con su crítica de la película de Abel Gance, este comentario no es tan importante, pero sería un ejemplo más del gusto de Prada por reivindicar un cine más artístico, pues al final de su artículo exige su estreno en España, en la línea con lo defendido en su crítica de Yo acuso.

También abordó Prada en sus artículos la situación de la industria cinematográfica, sobre todo en cuanto a la distribución y a los oficios relacionados con el cine. Aunque en la mayoría de sus colaboraciones destacaron los comentarios y las noticias sobre el mundo de las actrices, y los actores, sobre estas últimas, en algunos de sus textos encontramos interesantes reflexiones sobre la distribución de películas y los oficios en el cine. En un artículo publicado en El Fígaro el 26 de mayo de 1919²7, Prada aborda las consecuencias de la Primera Guerra Mundial para el mercado europeo de la distribución cinematográfica. Comienza su reflexión informando sobre el dominio estadounidense: «Los periódicos ingleses, franceses e italianos - particularmente los dos últimos- dan angustiosamente la voz de alarma ante el arrollador avance de las pujantes Casas americanas [...]». De nuevo, observamos la alusión a la prensa extranjera, lo que vendría a corroborar, al menos, un mínimo conocimiento de otros idiomas y la lectura de revistas especializadas que informaban sobre estos acontecimientos específicos del mercado cinematográfico.

Prada continua con el relato de la invasión de operadores («cinematografistas») estadounidenses en Europa, así como la apertura de filiales para la distribución y producción de los largometrajes norteamericanos («estudios» y «talleres»). Toda esta campaña de exportación de material cinematográfico estadounidense puede suponer una seria amenaza para Francia e Italia, en palabras de Prada: «Grande va a ser el esfuerzo que van a tener que realizar Francia e Italia - reinas un día del arte mudo- para contrarrestar la triunfal marcha de América [...]». A continuación, Prada expone las razones por las que ella considera que se van a imponer las películas de Hollywood: su consolidado star system, la inversión empresarial, la protección
[26] Desgraciadamente, desconocemos si Prada leyó directamente dicha prensa extranjera o simplemente recogió las frases de promoción de la distribuidora, lo que nos daría una valiosa información sobre su educación y pensamiento cinematográfico.

[27] Duquesa de Borelli, «Páginas cinematográficas» (El Fígaro, 26-05-1919), p. 2. 
[28] L. Alonso, «De arañas y moscas: la formación del sistema cine y los principios de la distribución cinematográfica en España» (Archivos de la Filmoteca, n. $\left.{ }^{\circ} 66,2010\right)$, pp. 131-145.

[29] I. Ribas, «El papel de la distribución en Cataluña durante la Primera Guerra Mundial», en A propósito de Cuesta. Escritos sobre los comienzos del cine español, 18961920 (Valencia, Ediciones de la Filmoteca, 2010), pp. 408-414. y apoyos gubernamentales y la exportación a otras cinematografías: «[...] viendo en ella [la industria hollywoodiense], no solo una fuente de ingresos inapreciables para la riqueza del país, sino también un instrumento de valor incalculable para el fomento y propaganda mundial [...] de otras industrias americanas». En efecto, Prada ya realiza una conexión entre la producción en serie de largometrajes y el marketing analizando el cine desde valores puramente económicos. Ante esta maquinaria industrial, Prada advierte sobre la reacción francesa para contener la invasión americana, consistente en la celebración en 1920 de una Exposición y un Congreso Internacional de Cinematografía, lo que nos daría un indicio de los primeros pasos para una legitimación institucional del cine en Europa a nivel internacional. Por su parte, Italia no parece poseer ningún plan concreto, aunque Prada informa de que su industria está realizando movimientos para volver a recuperar su primacía anterior.

A Carmen Prada no se le escapaba que, en este momento, la industria cinematográfica estaba sufriendo una profunda transformación. Así, a principios del siglo xx, comenzaba a consolidarse en Madrid el negocio del cine, sobre todo en cuanto a la exhibición y la distribución de películas. En efecto, en estos años, el número de salas dedicadas en exclusiva al cine aumenta, ubicándose la mayoría de ellas en los grandes ejes urbanos. Son los denominados pabellones cinematográficos, que habían surgido una década antes como grandes salas y que cambiarían la forma de asistir al cine y, por lo tanto, la recepción de las películas.

A su vez, estas salas pudieron ofrecer programas mucho más interesantes gracias a los cambios en la distribución de películas. Hasta 1910, la distribución estaba dominada por Barcelona, en la que se asentaban las sucursales de las principales casas extranjeras. En Madrid, tan solo se evidencia la presencia de las distribuidoras Juan Fuster y Trust Film. Pero, a partir de 1911 y hasta 1921, Madrid se convierte en el principal centro de distribución de la península, algo de lo que se benefició Carmen Prada al asistir a los «pases de prueba» y a los numerosos estrenos de la actualidad cinematográfica. Alonso ${ }^{28}$ cita las casas Miguel de Miguel, Ernesto González, Enrique de Castro, Julián Ajuria y Julio César como las principales distribuidoras a nivel nacional que, además, distribuían los largometrajes extranjeros en la capital. A su vez, Ribas ${ }^{29}$ estima que Madrid se convirtió en el principal centro comercial cinematográfico a la altura de 1916 (como dato significativo habría que mencionar que Pathé trasladó su sede central a Madrid), de tal manera que el mapa de la distribución en España quedaría configurado, a la altura de 1920, de la siguiente forma: Barcelona, como centro distribuidor para Cataluña, Aragón y Baleares; Madrid, para Castilla La Nueva, León, parte de Castilla La Vieja y Cáceres; Sevilla, para Andalucía, Badajoz, Canarias y norte de África; Valencia, para el País Valenciano y Murcia; Bilbao, para País Vasco, Navarra, parte de León y parte de Castilla La Vieja; y A Coruña, para Galicia y Asturias. 


\section{Carmen Prada y la modernidad}

Dejando a un lado las cuestiones industriales del negocio cinematográfico, resulta también interesante el artículo que Prada publicó el 21 de septiembre de 1919 en El Fígaro sobre los guionistas ${ }^{30}$. $\mathrm{Al}$ comienzo de su extenso reportaje, la periodista realiza una reivindicación del trabajo de los guionistas o «escritores de argumentos» con una referencia inmediata a las mujeres: «Queremos, linda lectora, ponerte en contacto con esos seres anónimos». Para Prada, existe un desconocimiento por parte del público sobre el trabajo de los guionistas, cuya razón fundamental es que no aparecen reflejados en los títulos de crédito de las películas:

Habrás observado que, por regla general, en las cintas se hace presentación de los intérpretes principales, del director de escena, del operador, hasta del traductor de los títulos, que... en algunos casos más valiera quedarse en la sombra... Pero del escritor de argumentos, ¿̇quién [sic] se acuerda?

Es esta invisibilidad de los guionistas la que Prada quiere superar otorgándoles la importancia que se merecen, frente a otros oficios ya consagrados como el de los actores y las actrices, los directores y directoras de escena, los operadores y operadoras y los traductores y traductoras de títulos. A su vez, Prada reivindica que existe una participación importante de mujeres en la escritura de guiones: «Como irás viendo, entre estos forzados de la pluma tiene lúcida representación el bello sexo a que pertenecemos».

Como ejemplo de guionistas recurre a la pareja formada por John Emerson y Anita Loos, dos de los guionistas más importantes de Hollywood en aquel momento. Al principio, hace una alusión a la unión matrimonial entre los dos guionistas, aunque no desde un punto de vista sensacionalista, sino como un elemento importante para su trabajo: «Nada más natural que la compenetración espiritual que entre ellos estableciera la cotidiana labor acabase en una atracción mutua, primero, y en algo más hondo, después». A su vez, Prada demuestra un conocimiento profundo de la vida artística de ambos guionistas cuando los introduce, aclarando que Emerson era un autor de dramas y comedias que había trabajado como director de escena en el teatro, mientras que Loos había tenido una formación autodidacta («escribía por intuición») y se había especializado como escritora de «argumentos fotodramáticos» para convertirse en una guionista en los primeros tiempos del cine. Prada alude a que escribió los argumentos de las primeras producciones de Douglas Fairbanks ${ }^{31}$.

Sin embargo, lo más relevante de este interesante acercamiento a la figura de los guionistas es la igualdad de géneros que propone Prada, pues entre Emerson y Loos lo que existe es una férrea compenetración en el trabajo, una complementariedad que es la base de su éxito: [3o] Duquesa de Borelli, «Páginas cinematográficas» (El Fígaro, 21-09-1919), p. 2.

[31] Esta alusión a los «argumentos fotodramáticos» nos induce a pensar en una íntima relación cultural entre el mundo de la fotografía y las novelas populares con la escritura de guiones cinematográficos. Es, de nuevo, una muestra más de las posibilidades que ofrecen los textos de Prada para un análisis historiográfico de la recepción del cine en las primeras décadas del siglo xx.

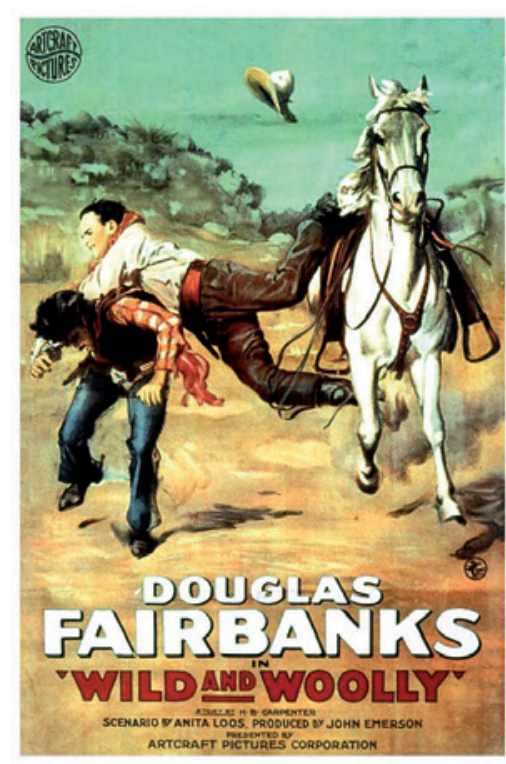

Cartel de Wild and Woolly (John Emerson, 1917). 


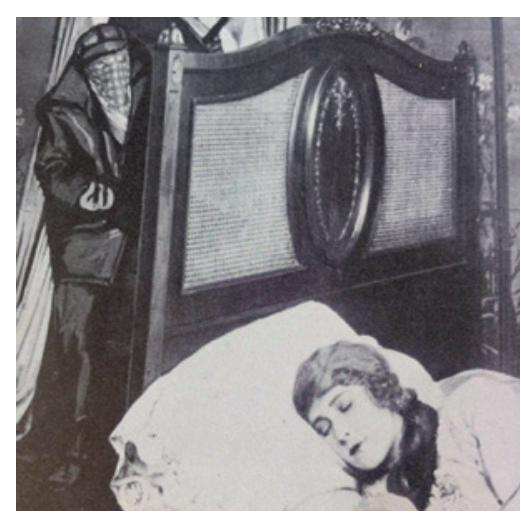

Fotograma de The Exploits of Eliane (Louis J. Gasnier, George B. Seitz, Leopold Wharton, Theodore Wharton, 1914), protagonizada por Pearl White.
John vio en Anita el talento creador, la intuición artística que el desarrollo de una obra cinematográfica requiere. Anita vio en John al experto en desarrollo de temas, al conocedor de multitud de recursos de efecto en la escena. Ella era el talento creador: la concepción y el alumbramiento. Él era el pulimentador. Cada uno [de ellos] por un lado estaba incompleto. Juntos se complementaban.

En las palabras de Prada observamos cierta modernidad cultural y moral asociada con oficios nuevos, diferentes. La modernidad y urbanidad que confieren su seña de identidad al cinematógrafo también plantea reflexiones en torno al papel laboral de la mujer y una reivindicación de la libertad creativa y la inteligencia femeninas. No obstante, es el único artículo de Prada en el que hemos encontrado una reivindicación evidente de la igualdad de género, al menos en la totalidad de fuentes consultadas para este artículo.

Aun así, Carmen Prada dedicó numerosas reseñas y reportajes a un género como el serial, que estaba íntimamente relacionado con la igualdad de género, como ha demostrado de manera excelente la profesora Dall'Asta ${ }^{32}$. Precisamente, fueron los seriales estadounidenses los que ocuparon la principal novedad en los programas de los cines de Madrid, como advertimos en los textos de Carmen Prada. El serial fue un producto cinematográfico de una gran originalidad y que causó una verdadera revolución dentro de la recepción del cine, a la vez que supuso el protagonismo de la mujer como agente creador y receptor del cine. Dall'Asta plantea la importancia del serial como elemento de cambio cultural y, a la vez, como producto transitorio hacia la propia institucionalización del cine. En concreto, la modernidad del serial no vendría solo señalada por la época en la que aparece, sino porque propone la visibilización de la nueva cultura femenina a través de las llamadas serial queens, las protagonistas de los seriales, que se convertirán en modelos femeninos. De hecho, Dall'Asta resalta la conexión entre las serial queen y la nueva mujer moderna o new woman, caracterizada por su dinamismo, su independencia económica y su actitud decidida, atributos todos ellos reservados al patriarcado. En efecto, las serial queen afirman el derecho de la mujer a la acción física mediante la velocidad y el desenfreno corporal, como ponen en evidencia los papeles interpretados por Pearl White, a la que Prada tenía entre una de sus actrices favoritas, como demuestra el hecho de que le dedicara un artículo en El Fígaro (01-01-1920) ${ }^{33}$. Las heroínas que interpretaba Pearl White en la pantalla afirmaban el derecho de la mujer a vivir experiencias excitantes y gratificantes al margen de su papel pasivo como madre y esposa. Muy al contrario, Pearl White

[32] M. Dall'Asta, «El serial», pp. 251-273.

[33] Duquesa de Borelli, «Páginas cinematográficas» (El Fígaro, 01-01-1920), p. 2 interpretaba mujeres seductoras, acróbatas, deportivas, revolucionarias, feroces y, por consiguiente, una amenaza para el patriarcado. De ahí que, hacia principios de los años veinte, la hegemonía de las serial queens fuera despareciendo y se impusiera un movimiento censor que transformó el serial en un género de acción masculino. 


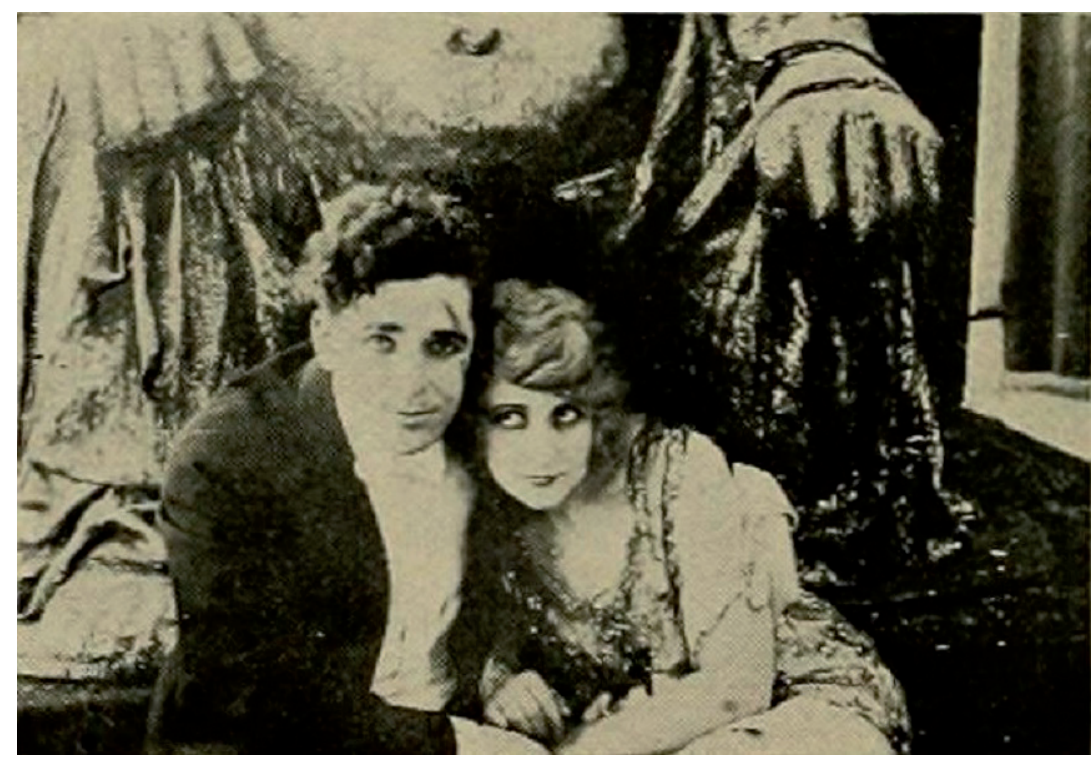

Pearl White y Crane Wilbur en The Perils of Pauline (Louis J. Gasnier y Donald McKenzie, 1914).

Carmen Prada parece adaptarse a esta imagen de la mujer moderna debido a su educación, a su más que evidente pertenencia a la clase media burguesa, a su participación en los nuevos hábitos urbanos y a su trabajo como periodista. De hecho, la historiografía ha ubicado en los años veinte la plenitud del nuevo perfil de mujer moderna, las que en su momento eran llamadas flapper en Estados Unidos y Gran Bretaña, garçonne en Francia o maschietta en Italia, todos ellos procedentes de términos masculinos. Esta mujer moderna se caracterizaba por la independencia laboral y económica gracias a los beneficios de una mejor formación cultural derivada de la pertenencia a los sectores acomodados de la sociedad, a su vocación profesional y a una conciencia política de ideología liberal y progresista. Su defensa de la feminidad, su libertad y su independencia se reflejaban en una liberación sexual revolucionaria al desafiar la imagen patriarcal que asocia a la mujer con la fertilidad y el cuidado del hogar. De ahí que adoptara los nuevos hábitos urbanos como el deporte, el ocio (fumar y alternar) o la moda, con un aspecto físico que rechazaba la corpulencia como canon y reivindicaba una delgadez que ponía en entredicho el arquetipo de madre, esposa, hermana e hija ${ }^{34}$.

Esta nueva cultura femenina permitió la configuración de un movimiento feminista más consolidado en España. En los años veinte, «el problema feminista», término utilizado para referirse al feminismo, adoptó tres líneas generales de actuación: el reconocimiento de la opresión que ejercía el patriarcado sobre la mujer, el rechazo a la posición secundaria de la mujer en la sociedad y la denuncia de la falta de educación. Junto a este feminismo progresista, surgió un feminismo católico y conservador que se centraba en alcanzar logros eco-
[34] S. Mangini González, Las modernas de Madrid. Las grandes intelectuales españolas de la vanguardia (Barcelona, Península, 2001). 
[35] M. ${ }^{a}$ J. Matilla Quiza y E. Frax Rosales, «Géiseres femeninos: las mujeres irrumpen con fuerza en la vida madrileña», en El Madrid de las mujeres. Avances hacia la visibilidad (1833-1931). II (Madrid, Comunidad de Madrid, 2007), pp. 147-176.

[36] C. Prada, «De maternología. Pro infancia» (El Día, 3010-1918).

[37] Duquesa de Borelli, «El niño en el cine» (Cinema, n. ${ }^{\circ}$ 1, enero-febrero de 1920). nómicos mediante la protesta contra la subida de impuestos y la reivindicación de la creación de escuelas profesionales para mujeres, pero que aceptaba, también, el poder del patriarcado, no denunciaba su opresión y mostraba cierta ambigüedad a la hora de defender el feminismo. No obstante, el feminismo triunfó gracias al asociacionismo de las mujeres. En Madrid, este asociacionismo permitió la aparición de espacios de sociabilidad para la mujer de clase media, donde se abandonaba la tradicional vida familiar del hogar y se participaba en actividades educativas, culturales, filantrópicas y sociales para difundir el feminismo y fortalecer el papel de la mujer como agente social y cultural. Es el caso de la Asociación Nacional de Mujeres Españolas (ANME, 1918), de María Espinosa e Isabel Oyarzábal; la Juventud Universitaria Feminista (JUF, 1921), de María de Maeztu y Clara Campoamor; la Acción Católica de la Mujer (ACM), de la Condesa de Gavia; la Residencia de Señoritas (1915), de María de Maeztu; o el Lyceum Club, de nuevo con Maeztu, Oyarzábal y Victoria Kent ${ }^{35}$.

No obstante, no era necesario militar en la vanguardia o pertenecer a una asociación femenina para defender los derechos y la igualdad de la mujer. Carmen Prada parece haber mantenido una defensa de los derechos de la mujer no solo por su trabajo como profesora en la escuela de mujeres adultas de Barcelona, contribuyendo a la educación de las mujeres junto a personalidades tan significativas para el movimiento feminista español como Clara Campoamor, sino también por un texto que escribió en el periódico El Día antes de iniciar su actividad como crítica de cine. En dicho texto, fechado el 30 de octubre de $1918^{36}$, Carmen Prada defiende la instalación de «casas-cuna» para los recién nacidos en Madrid para, con ello, permitir que las madres continúen con sus jornadas laborales y no tengan que abandonar sus trabajos para dedicarse en exclusiva a la vida doméstica. En este texto es significativo que cite a Margarita Nelken, una de las grandes figuras del feminismo en aquel momento y con quien seguramente mantuvo algún tipo de relación, ya que ambas escribían por aquellas fechas en el mismo periódico. Además, esta reivindicación ya la había remitido a la revista La Escuela Moderna en 1916, cuando elaboró un informe como agregada a la Inspección Médico-Escolar en Madrid. Aun así, por el momento no podemos establecer una vinculación directa entre Prada y el asociacionismo femenino.

Como hemos constatado, Prada parece cuestionar la moralidad imperante en la cultura del momento, sobre todo en relación con el cine. Así, en un artículo publicado en la revista Cinema en enero-febrero de $1920^{37}$, Prada defiende la moralidad y las virtudes educativas del cinematógrafo frente a la censura moral contra él. No está de acuerdo con la supuesta superioridad educativa del teatro frente al cine. Para ella, el teatro resulta, en la mayoría de las ocasiones, artificioso y falso, con argumentos pomposos, afectados, ridículos y de un humor grosero; además, lo considera demasiado elitista y alega: «que ellos [los espectadores] no entienden por no estar al alcance de su intelecto, todavía, penetrar en las grandiosidades o mezquindades del pensamiento de los autores».

Más tarde, defiende el cine como auxiliar educativo gracias a sus escenarios naturales, que permiten el conocimiento de países, monumentos y la cul- 
tura de los países extranjeros ilustrando al público infantil. Además, defiende la moralidad de las películas de crímenes y de acción debido a su final ejemplar, pues los protagonistas a menudo son castigados por sus malos actos, ya sea por medio de la justicia o de la conciencia religiosa. Para Prada, la existencia de estos finales moralizadores y la propia autocensura que practican las empresas productoras y los gobiernos son suficientes para garantizar la moralidad de las películas que se exhiben en los cines, sin necesidad de cambiar los programas de las salas con películas consideradas «más pedagógicas», lo cual ella considera un error desde el punto de vista del marketing, ya que la existencia de los llamados «días blancos» (para el público infantil) a menudo conlleva una escasa taquilla, puesto que las películas son poco atractivas para el público. Así, termina con una defensa ferviente de la moralidad del cine:

iLa moralidad! ¿Quién es capaz de decir dónde empieza y dónde acaba? iUn beso! Pero, ¿̇por qué tanto horror al beso? Cuando yo veo a dos artistas besarse en la pantalla, no siento el menor rubor ni pasa por mi imaginación idea alguna que despeje a la expresión más hermosa, más suave, de cariño, de toda su ingenuidad, de toda su poesía, de toda su grandeza... [...]. Para ellos [los niños y las niñas] no hay allí más que dos personas que se aman, que se quieren y se besan como ellos lo ven en sus casas, y en las de la familia, y en las de las amistades, y hasta en la calle, a todas horas, entre personas que se quieren...

Para terminar este sucinto recorrido por algunos de los escritos más relevantes de Prada sobre el mundo del cine, nos gustaría aludir a un artículo publicado en Mundo Gráfico, quizás el último que Prada redactó como periodista cinematográfica, fechado el 5 de octubre de $1921^{38}$, donde realiza un resumen del origen histórico del cinematógrafo. En todo momento, lo que llama la atención de este texto es el conocimiento de Prada sobre lo cinematográfico y, quizás lo más interesante, la firme voluntad erudita de Prada volviendo a reivindicar la profesionalización de la crítica cinematográfica. Por ejemplo, al principio de su repaso por la breve historia de los inicios del cine, descarta el origen antiguo del fenómeno cinematográfico: «Infinitas y encontradas son las versiones que respecto del origen del cinematográfico se han expuesto. Algunas retrotraen su invención a la más remota antigüedad». No sabemos a qué «antigüedad»se refiere Prada, pues no especifica el momento histórico, como tampoco añade ninguna información a propósito de esas «versiones» sobre el origen del cinematógrafo. No obstante, justifica su rechazo a esta tesis basándose en la falta de datos fiables: «Ahora bien: son tan ambiguos los datos en que se apoyan sus autores, que preferimos no remontarnos tanto y partir de una época relativamente próxima: el siglo xvi».

A partir de aquí, Prada realiza un recorrido, pudiéramos decir ya canónico, por la evolución tecnológica del cinematógrafo: la linterna mágica de Kircher (s. xvI), el revólver fotográfico de Jansen (1874), la cronofotografía de Muybridge (1877) (aunque introduce un dato erudito al aclarar que antes de Muybridge ya se había aplicado la cronofotografía por parte de Du-Monts), el primer aparato cinematográfico de Marcy (1878) ${ }^{39}$, la aplicación de la obtu-
[38] Duquesa de Borelli, «Peliculerías. Un poco de historia» (Mundo Gráfico, 05-10-1921).

[39] Este es un ejemplo del tipo de rigor y erudición que contienen los escritos de Prada: «Marcy construye en 1878 el que pudiéramos llamar primer aparato cinematográfico, después de estudiar profundamente, perfeccionándolo, el método cronofotográfico - cuya gloria corresponde en principio á DuMonts- empleado por Muybridge, americano». 


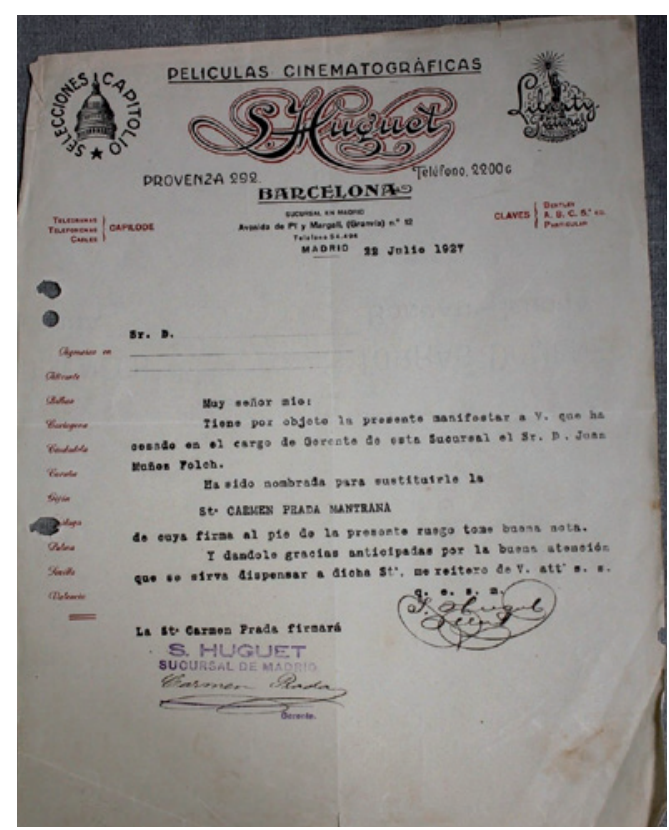

Documento acreditativo de la contratación de Carmen Prada por parte de S. Huguet. ración mecánica por parte de Anschutz (1884), el kinetoscopio de Edison (1894) a partir del fenakisticopio de Plateau; $y$, por último, el cinematógrafo de los hermanos Lumière (1895), culminación de todo este trayecto tecnológico: «aparato reversible para tomar y proyectar vistas animadas a un numeroso núcleo de espectadores [...], fue la verdadera base del Cinematógrafo que conocemos».

Sin embargo, al final de todo el artículo, Prada propone un origen cultural del cine alejado de la erudición tecnológica y asociado con los recuerdos de infancia:

Cuando todavía no habíamos empezado las tareas escolares, corrían de mano en mano [...] unos divertidos libritos, formados de hoja de cartulina, en cada uno de los cuales había un dibujo en negro, que presentaba los personajes en distintas actitudes. Bastaba hacer girar sus hojas con rapidez para reproducir graciosas escenas animadas.

\section{Conclusión}

Este último texto nos da una pista sobre la transcendencia del trabajo como periodista de Carmen Prada, pues, al contrario que la mayoría de los periodistas cinematográficos del momento, Carmen Prada sí que se inició exclusivamente en el cine como espectadora, como periodista y como profesional de la industria. Esta prolífica actividad la vincula con la consolidación de la crítica cinematográfica dentro del periodismo, un proceso en el que Carmen Prada parece jugar un importante papel, ya que su producción, variedad y presencia en los diarios y revistas madrileños del momento la convierten en una pieza fundamental de este periodismo cinematográfico. Además, como hemos advertido, su trabajo la dotaba de una independencia económica y una posición cultural cercana a la de la mujer moderna del momento, a la vez que realizaba una defensa del progreso tecnológico con su probada cinefilia y estaba al tanto de la modernidad cultural en cuanto a la moda y al aspecto físico, gracias a sus referencias a la imagen de las estrellas cinematográficas.

Al margen de su militancia feminista, aspecto que hoy en día desconocemos, es evidente la importancia historiográfica de Carmen Prada para el estudio del cine en Madrid y en España. Como mujer moderna, Prada realizó una defensa de lo urbano y del cine a partir de una cultura y una educación superior que le permitieron desarrollar su actividad como periodista en algunos de los principales medios del momento. Su trayectoria como periodista cinematográfica fue sólida por el número de años que estuvo ejerciendo dicha labor, por su permanencia 
al frente de las cabeceras, por la cantidad de artículos que escribió y en comparación con otras periodistas que también escribieron sobre cine en esos años, como Carmen de Burgos o M. ${ }^{\mathrm{a}}$ Luz Morales ${ }^{40}$. Además, la variedad temática de su trabajo como periodista nos ofrece un material rico y complejo que necesita de un análisis más profundo que el expuesto en este artículo y la posiciona como una de las primeras periodistas que ejerció en exclusiva la crítica de cine en Madrid a través de un discurso reflexivo en el que la opinión, la erudición y la información conviven con una defensa del cine como arte y entretenimiento, convirtiendo sus textos en un material de suma importancia para conocer el estado de la recepción del cine en Madrid durante los años veinte.

\section{BIBLIOGRAFÍA}

Alonso, L., «De arañas y moscas: la formación del sistema cine y los principios de la distribución cinematográfica en España» (Archivos de la Filmoteca, n. ${ }^{\circ}$ 66, 2008), pp. 131-145.

Anónimo, «Las profesoras de taquigrafía y mecanografía» (El Mundo Taquigráfico, n. ${ }^{\circ}$ 167, 15-02-1914), pp. 33-39.

-, «Profesoras de taquigrafía» (La Vanguardia, 18-02-1914), p. 10.

-, «Notas locales» (La Vanguardia, 14-01-1918), p. 6.

-, «De enseñanza nacional» (La Vanguardia, 21-08-1924), p. 16.

-, «Varios actos de propaganda política y social» (El Sol, 31-01-1933).

-, «Actos de propaganda política» (La Libertad, 31-01-1933).

-, «Vida docente» (La Vanguardia, 16-10-1936), p.8.

-, «Comunicados» (Solidaridad Obrera, 11-12-1937), p. 7.

Binimelis, M., «Perspectivas teóricas en torno a la representación de las mujeres en el cine: una breve aproximación histórica» (Secuencias, n. ${ }^{\circ}$ 42, 2015), pp. 9-34, disponible en <doi: http://dx.doi.or/10.15366/secuencias2016.42.001>.

DALL'Asta, M., «El serial», en Historia mundial del cine. Vol. 1. Estados Unidos. Tomo 1 (Madrid, Akal, 2011), pp. 251-273.

Duquesa De Borelli, «Hojas sueltas de mi álbum» (El Día, 18-11-1918), p. 4.

-, «Hojas sueltas de mi álbum» (El Día, 30-12-1918), p. 4.

-, «Páginas cinematográficas» (El Fígaro, 26-05-1919), p. 2.

-, «Páginas cinematográficas» (El Fígaro, 31-08-1919), p. 2.

-, «Páginas cinematográficas» (El Fígaro, 21-09-1919), p. 2.

-, «Páginas cinematográficas» (El Fígaro, 01-01-1920), p. 2.

-, «El niño en el cine» (Cinema, n. ${ }^{\circ}$ 1, ene-feb 1920).

-, «Peliculerías» (Mundo Gráfico, 01-06-1921).

-, «Peliculerías. Un poco de historia» (Mundo Gráfico, 05-10-1921).

García Carrión, M., Por un cine patrio. Cultura cinematográfica y nacionalismo español (1926-1936) (Valencia, Publicacions de la Universitat de València, 2013).

Gledhill, C., «An Ephemeral History: Women and British Cinema Culture in the Silent Era», en Researching Women in Silent Cinema New Findings and Perspectives (Bolonia, Alma Mater Studiorum, 2013), pp. 131-148.

Gómez Mesa, L., «Gracias, infinitas gracias, señorita Carmen Prada» (Popular Film, n. ${ }^{0}$ 34, 24-03-1927), pp. 1-2.
[40] Véase A. Rodrigo, $\mathrm{Mu}$ jeres para la historia. La España silenciada del siglo $X X$ (Madrid, Compañía Literaria, 1996). 
Hernández Eguíluz, A., Testimonios de huecograbado. El cine en la $2^{a}$ República y su prensa espacializada (1930-1939) (Valencia, Ediciones de la Filmoteca, 2009).

InsuA, A., «El iYo acuso!, de Abel Gauce [sic]». (La Correspondencia de España, o8-011921).

MANGini GonZÁlez, S., Las modernas de Madrid. Las grandes intelectuales españolas de la vanguardia (Barcelona, Península, 2001).

Matilla Quiza, M. a J. y Frax Rosales, E., «Géiseres femeninos: las mujeres irrumpen con fuerza en la vida madrileña», en El Madrid de las mujeres. Avances hacia la visibilidad (1833-1931). II (Madrid, Comunidad de Madrid, 2007), pp. 147-176.

Mencheta, «Doña Teresa Luzzati dijo que la mujer debe decidirse a "manejar" el voto femenino, que es un arma de dos filos» (La Nación, 20-06-1932), p. 2.

Minguet Batllori, J. M., «Las vanguardias históricas y el cine español», en Un siglo de cine español (Madrid, Academia de las Artes y las Ciencias Cinematográficas, 2000), pp. 65-79.

-, Paisaje(s) del cine mudo en España (Valencia, Ediciones de la Filmoteca, 2008).

Nielfa Cristobal, G., «Las relaciones de género: Imágenes y realidad social» (Arbor, n. ${ }^{\circ}$ 666, junio de 2001), pp. 431-460.

Palomo, M. P, «Colombine y el cine mudo en España (La mejor filme)» (Arbor, n. ${ }^{\circ}$ CLXXXVI, junio de 2010), pp. 21-30.

PradA, C., «Memoria presentada al Ilmo. Sr. Director General de la Primera Enseñanza por la profesora especial de mecanografía y taquigrafía de las escuelas de adultas de Barcelona, D. ${ }^{\text {a }}$ Carmen Prada Mantrana, agregada a la Inspección Médico-Escolar de Madrid para estudiar los problemas de higiene escolar (1)» (La Escuela Moderna. Revista Pedagógica y Administrativa de Primera Enseñanza, n. ${ }^{\circ}$ 298, 01-06-1916), pp. 364-370.

-, «De maternología. Pro infancia» (El Día, 30-10-1918).

—, «De Maternidad. Pro-infancia» (El Día, 22-11-1918).

RIBAS, I., «El papel de la distribución en Cataluña durante la Primera Guerra Mundial», en A propósito de Cuesta. Escritos sobre los comienzos del cine español 1896-1920 (Valencia, Ediciones de la Filmoteca, 2010), pp. 408-414.

Rodrigo, A, Mujeres para la historia. La España silenciada del siglo XX (Madrid, Compañía Literaria, 1996).

Seonne, M. C. y SÁrz, M. ${ }^{a}$ D., Historia del periodismo en España. 3. El siglo XX: 18981936 (Madrid, Alianza Editorial, 1998).

SERnA, L. I., «Descripción», en Media History Digital Library. Disponible en: <http:// lantern.mediahist.org/catalog/cinemundial19unse_0154/>, 2013.

Soто, B., «Volverse invisible. Cinematógrafo, modernidad, mujer y trabajo», en Cinema i modernitat: les transformacions de la ercepció (Girona, Fundació Museu del Cinema-Col-lecció Tomàs Mallol / Ajuntament de Girona, 2008), pp. 155-160.

Torres, .M., «Valores positivos» (Arte y Cinematografía, n. ${ }^{0} 300,1926$ ).

-, «Apuntes para la historia del cinema español. Juan Antonio Cabero, decano de los periodistas cinematográficos de Madrid» (Cinegramas, n. ${ }^{\circ}$ 67, 22-12-1935).

ZuRIÁn, F. A. (coord.), Construyendo una mirada propia. Mujeres directoras en el cine español. De los orígenes al año 2000 (Madrid, Síntesis, 2015).

Recibido: 12 de junio de 2017

Aceptado para revisión por pares: 14 de noviembre de 2017

Aprobado para publicación: 25 de junio de 2018 


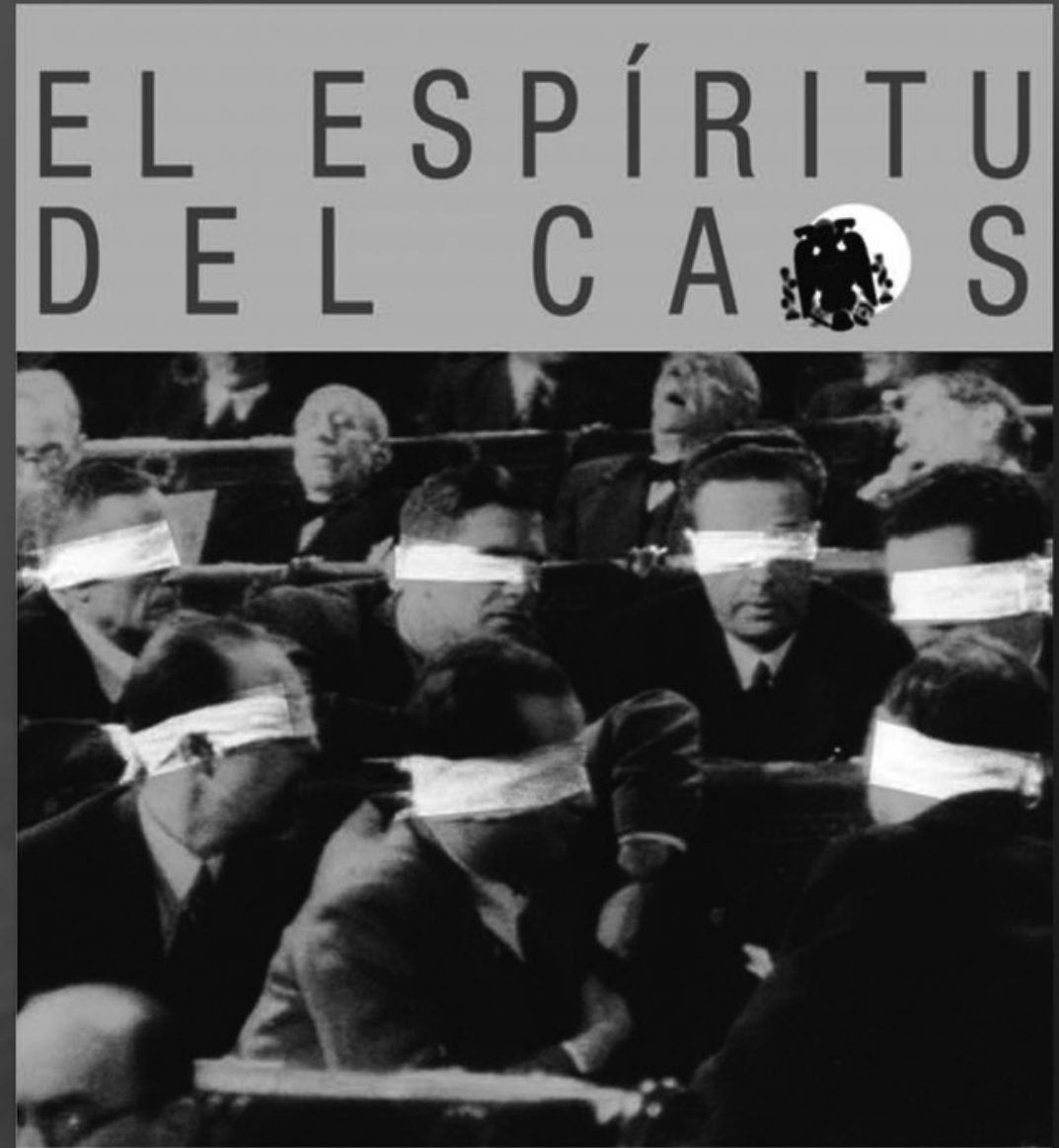

REPRESENTACIÓN Y RECEPCIÓN DE LAS IMÁGENES DURANTE EL FRANQUISMO

(Una recopilación de Secuencias. Revista de Historia del cine) LAURA GÓMEZ VAQUERO Y DANIEL SÁNCHEZ SALAS (EDS.)

Recopilación de artículos aparecidos en Secuencias. Revista de Historia del Cine acerca de una de las etapas del audiovisual más estudiadas en nuestro pais, aquella que coincide con la dictadura franquista.

Los textos incluyen algunos de los descubrimientos más insólitos en el terreno del audiovisual y constituyen una muestra de las perspectivas que se pueden adoptar en la comprensión de los distintos productos cinematográficos y televisivos realizados durante esos años.

592 páginas.

ISBN 978-84-96582-36-1

INFORMACIÓN Y VENTA: OCHO Y MEDIO, LIBOS DE CINE. Martín de los Heros, 11. 28008 MADRID

Tel. 9155906 28, tax 9154006 72, libros@ochoymedio.com 